\title{
Diffuse Lipomatosis of Face
}

\author{
${ }^{1}$ Vibhuti S Mhatre, ${ }^{2}$ Jigna Pathak, ${ }^{3}$ Shilpa Patel, ${ }^{4}$ Niharika Swain, ${ }^{5}$ Adil Gandevivala
}

\section{ABSTRACT}

Congenital infiltrating lipomatosis is a distinct clinicopathological entity. It is a type of lipomatosis that is usually found at birth or early after birth. It is designated by a collection of nonencapsulated, mature adipocytes that infiltrate local tissues, leading to craniofacial deformities. Due to its diffuse infiltration and involvement of important facial structures, a complete surgical excision is often impossible. We report a case of a 5 -year-old female patient presenting with a painless swelling on the left side of her face.

Keywords: Diffuse lipomatosis, Infiltrating lipomatosis, Lipomatous tumor.

How to cite this article: Mhatre VS, Pathak J, Patel S, Swain N, Gandevivala A. Diffuse Lipomatosis of Face. J Contemp Dent 2017;7(3):185-187.

\section{Source of support: Nil}

Conflict of interest: None

\section{INTRODUCTION}

Congenital infiltrating lipomatosis is a distinct clinicopathological entity. It is a type of lipomatosis that is usually found at birth or early after birth. ${ }^{1}$ It comes under the subset of lipomatous tumor-like lesions and is designated by collection of nonencapsulated, mature adipocytes that infiltrate local tissues, leading to craniofacial deformities and is prone to recur postsurgery. ${ }^{2}$ The tumor-like lesion is congenital in origin and presents in infancy or early childhood as unilateral facial asymmetry. ${ }^{3}$ Until date, fewer than 50 cases have been reported in English literature. ${ }^{2,4}$ We report a case of a 5-year-old female patient presenting with a painless swelling on the left side of her face.

\footnotetext{
${ }^{1}$ Postgraduate Student, ${ }^{2}$ Professor, ${ }^{3}$ Professor and Head ${ }^{4}$ Reader, ${ }^{5}$ Senior Lecturer

${ }^{1-4}$ Department of Oral Pathology and Microbiology, Mahatma Gandhi Mission's Dental College and Hospital, Navi Mumbai Maharashtra, India

${ }^{5}$ Department of Oral and Maxillofacial Surgery, Mahatma Gandhi Mission's Dental College and Hospital, Navi Mumbai Maharashtra, India

Corresponding Author: Vibhuti S Mhatre, Postgraduate Student, Department of Oral Pathology and Microbiology Mahatma Gandhi Mission's Dental College and Hospital, Navi Mumbai, Maharashtra, India, Phone: +919920900459, e-mail: vibsm.vm@gmail.com
}

\section{CASE REPORT}

A 5-year-old female patient reported to our department with a chief complaint of a painless swelling on the left middle and lower third of the face. The swelling was noticed by her parents at birth and was gradually increasing in size with age. Patient did not have any difficulty in speech or loss of hearing. There was no other relevant history.

Extraoral examination revealed gross facial asymmetry due to a solitary diffuse swelling on the left side of the face, extending from left zygomatic arch up to the left inferior border of the mandible (Fig. 1). Borders were indistinct and the skin over the swelling was normal. On palpation, there was no increase in surface temperature and the swelling was soft, nontender, noncompressible, and nonpulsatile. No lymph nodes were palpable. Magnetic resonance imaging of the patient showed hyperintense lesion obliterating left maxillary sinus in $\mathrm{T} 1$ images with subcutaneous fat deposition. Based on these findings, a provisional diagnosis of congenital diffuse lipomatosis was made. Patient was referred to the Department of Oral \& Maxillofacial Surgery for biopsy.

Grossly, several bits of soft tissue were received with the largest rectangular bit, blackish white color, measuring $2.5 \times 1.0 \times 1.0 \mathrm{~cm}$. Histopathological examination revealed hematoxylin and eosin-stained soft tissue section showing sinus lining comprising ciliated pseudostratified squamous epithelium with focal hyperplasia. The underlying connective tissue stroma showed varying degrees of inflammatory cell infiltration, minor salivary

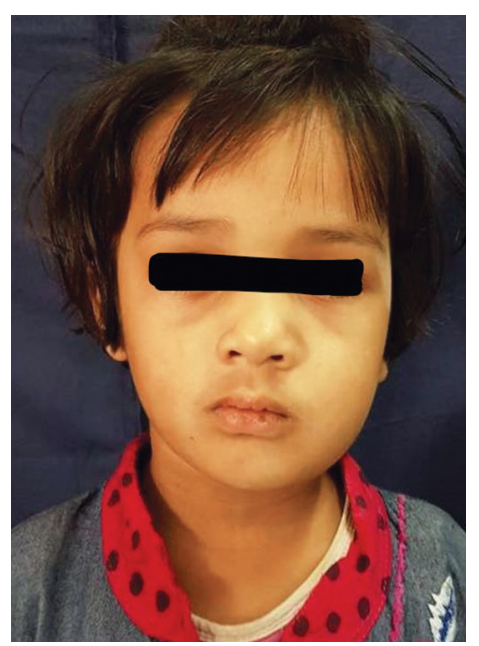

Fig. 1: Clinical photograph of a patient with unilateral facial swelling on the left side 


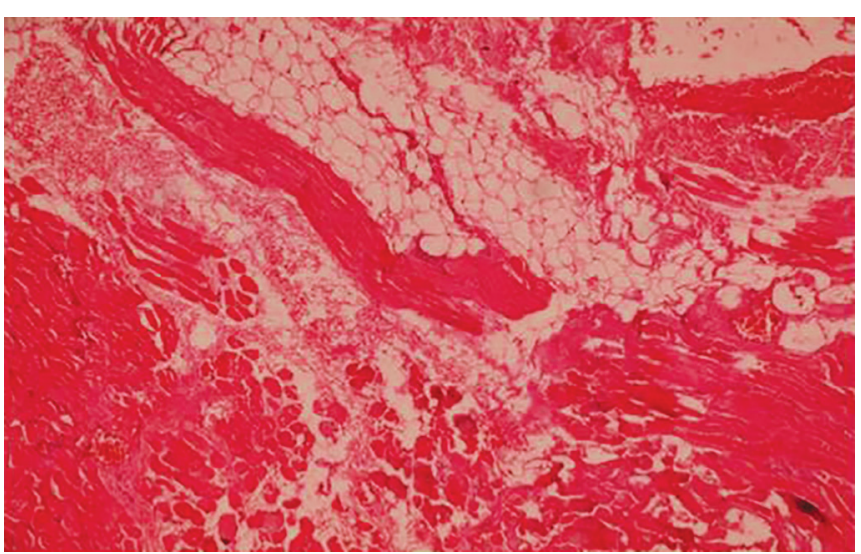

Fig. 2: Low-power photomicrograph showing mature adipocytes infiltrating surrounding structures

gland ducts with squamous metaplasia, and hemorrhage. The lesional tissue showed uncapsulated subcutaneous fat comprising lobular arrangement of adipocytes with infiltration to surrounding structures like muscle (Figs 2 and 3). The lesional fat cells with varying amounts of lipid inclusion vacuoles, peripheral rim of eosinophilic cytoplasm, and inconspicuous nucleus were intimately placed with the neuromuscular bundles. Based on these findings, the lesion was histopathologically diagnosed as diffuse lipomatosis of face, which was compatible with the clinical diagnosis. Excision of the lesion was done. However, recurrence could not be assessed as the patient was lost to follow-up.

\section{DISCUSSION}

Diffuse or infiltrating lipomatosis was defined by Enzinger and Weiss ${ }^{5}$ as a rare, diffuse overgrowth of mature adipose tissue that usually affects large portions of an extremity or the trunk. ${ }^{5}$ Classification given by Enzinger and Weiss composed of six entities: Diffuse lipomatosis, pelvic lipomatosis, symmetric lipomatosis (Madelung's disease), adiposis dolorosa (Dercum's disease), steroid lipomatosis, and nevus lipomatosus. Congenital infiltrating lipomatosis of the face (CIL-F) was not included in the classification by Enzinger and Weiss, and it was first described by Slavin et $\mathrm{al}^{3}$ in 1983, as a particular entity termed "congenital infiltrating lipomatosis of the face." It differentiates from the other lipomatosis in its exclusive facial location, effects on adjacent structures, congenital nature, and specific histological characteristics. ${ }^{6}$

Earlier studies by Slavin et $\mathrm{al}^{3}$ and de Rosa et $\mathrm{al}^{7}$ have described the following characteristics of CIL-F: (1) nonencapsulated proliferation of mature adipose tissue, (2) diffuse infiltration of muscle and adjacent soft tissue, (3) presence of fibrous tissue, various nerve bundles, and vessels with thickened wall, (4) the absence of lipoblasts and signs of malignancy, despite having a

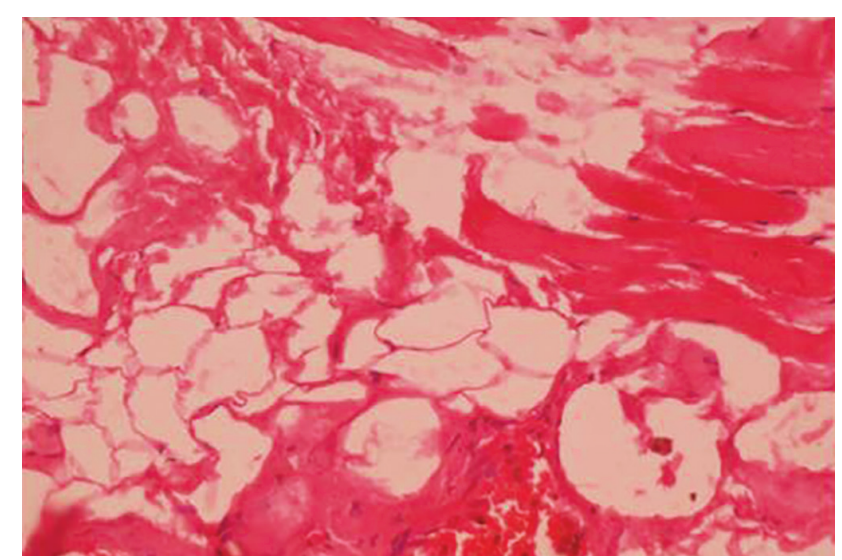

Fig. 3: High-power photomicrograph showing mature adipocytes infiltrating muscle

fast growth rate, (5) hypertrophy of adjacent bone, and (6) being congenital in origin with a propensity to recur after surgical excision.

Etiological factors contributing to this condition, which were proposed in the previous literature, include hamartomatous origin, ${ }^{3}$ degenerative processes with fatty transformation, ${ }^{1}$ cytomegalovirus infection, ${ }^{8-10}$ alterations in the neural tube during embryo development, ${ }^{11}$ trauma, and chronic irradiation. ${ }^{12}$ Sporadic or spontaneous somatic mutations at a mosaic state may possibly be responsible for giving rise to adipocytic stem cell to produce infiltrated lipomatosis. These mutated cells may alter the production of tissue growth factor or change the response to the receptor response, leading to aberrant formation of mucosal neuroma, bony growth, and tooth development. ${ }^{10}$ Abnormalities in chromosome 12 also may be implicated in lipomatous change in CIL-F. ${ }^{10}$ However, the exact pathogenesis of the condition is unclear. ${ }^{12}$

The CIL-F is a disorder that typically presents at birth or in early childhood as a unilateral swelling of the cheek with ill-defined borders. Though congenital, it is not hereditary. Diagnosis of the majority of the cases occurs within 2 years of life. The age of presentation varies from 3 months to 53 years. No gender predilection is noted. Slight predilection for occurrence on the left side. ${ }^{13}$ Patients usually present with a diffuse large swelling on one side of the face that is soft, fluctuant, and nontender. The clinical presentation of facial lipomatosis is usually in the form of unilateral hypertrophy of soft tissues of the face, most commonly the cheek, with underlying fat infiltration and skeletal overgrowth, ${ }^{1,3,7,12,14}$ macrodontia on the affected side, ${ }^{3,14-16}$ abnormal root formation, ${ }^{15}$ early eruption of deciduous and permanent teeth on the affected side ${ }^{14,17}$ macroglossia, ${ }^{14,17}$ and protuberances on the tongue and buccal mucosa, which are representative of underlying mucosal neuromas. ${ }^{14,17}$ Our patient was a 5-year-old female showing unilateral hypertrophy of facial soft tissues. 
The histopathologic features include a nonencapsulated lesion with proliferating mature adipose tissue, which is surrounded by a dense capillary network. There is diffuse infiltration of adjacent soft tissue and presence of fibrous tissue with various nerve bundles and thickened wall vessels. The absence of lipoblasts and signs of malignancy despite a rapid growth rate is observed. It may also show hypertrophy of subjacent bone. ${ }^{1,3,7}$ Our case also revealed uncapsulated lesional tissue comprising lobular arrangement of adipocytes with infiltration to surrounding structures.

The treatment options available are liposuction and surgical excision. Treatment is primarily for esthetic reasons. ${ }^{11,18,19}$ Although the tumors are benign, the rate of recurrence is very high, up to $58.6 \%$ after surgical excision. ${ }^{10}$

\section{CONCLUSION}

Congenital infiltrating lipomatosis of the face is a rare benign disorder of lipomatous tissue in infancy or childhood. When patients with facial asymmetry are reported, this should be considered. Thorough clinical examination, imaging studies, and histopathological examination help in the appropriate diagnosis. The chief motive of surgery is to improve the cosmetic appearance of the face rather than to eradicate the tumor.

\section{REFERENCES}

1. Chen CM, Lo LJ, Wong HF. Congenital infiltrating lipomatosis of the face: case report and literature review. Chang Gung Med J 2002 Mar;25(3):194-200.

2. Singh K, Sen P, Musgrove BT, Thicker N. Facial infiltrating lipomatosis: a case report and review of literature. Int J Surg Case Rep 2011 Jun;2(7):201-205.

3. Slavin SA, Baker DC, McCarthy JG, Mufarrij A. Congenital infiltrating lipomatosis of the face: clinicopathologic evaluation and treatment. Plast Reconstr Surg 1983 Aug;72(2):158-164.

4. Rajeswaran R, Murthy J, Chandrasekharan A, Joseph S. Case report: congenital infiltrating lipomatosis of face. Indian J Radiol Imaging 2008 Dec;18(4):306-309.
5. Weiss, S.; Goldblum, J. Enzinger and Weiss's soft tissue tumors. 5th ed. St Louis: Mosby; 2008. pp. 429-466.

6. Bouletreau P, Breton P, Friedel M. Congenital infiltrating lipomatosis of the face: case report. J Oral Maxillofac Surg 2000 Jul;58(7):807-810.

7. De Rosa G, Cozzolino A, Guarino M, Giardino C. Congenital infiltrating lipomatosis of the face. J Oral Maxillofac Surg 1987 Oct; $45(10): 879$.

8. Donati L, Candiani P, Grappolini S, Klinger M, Signorini M. Congenital infiltrating lipomatosis of the face related to CMV infection. Br J Plast Surg 1990 Jan;43(1):124-126.

9. Patel RV, Gondalia JS. Congenital infiltrating lipomatosis of the face (comment letter). Br J Plast Surg 1991;44:157-158.

10. Balaji SM. Congenital diffuse infiltrating facial lipomatosis. Ann Maxillofac Surg 2012 Jul-Dec;2(2):190-196.

11. Heymans $\mathrm{O}$, Ronsmans $\mathrm{C}$. Congenital infiltrating lipomatosis of the face. Eur J Plast Surg 2005;28:186-189.

12. Urs AB, Augustine J, Kumar P, Arora S, Aggarwal N, Sultana N. Infiltrating lipomatosis of the face: a case series. J Nat Sci Biol Med 2013 Jan;4(1):252-257.

13. Shenoy AR, Nair KK, Lingappa A, Shetty KS. Congenital infiltrating lipomatosis of face: case report and review of literature. J Indian Soc Pedod Prev Dent 2015 Apr-Jun;33(2): 156-160.

14. Padwa BL, Mulliken JB. Facial infiltrating lipomatosis. Plast Reconstr Surg 2001 Nov;108(6):1544-1554.

15. Mac Millan AR, Oliver AJ, Reade PC, Marshall DR. Regional macrodontia and regional bony enlargement associated with congenital infiltrating lipomatosis of the face presenting as unilateral facial hyperplasia. Int J Oral Maxillofac Surg 1990 Oct;19(5):283-286.

16. Kang N, Ross D, Harrison D. Unilateral hypertrophy of the face associated with infiltrating lipomatosis. J Oral Maxillofac Surg 1998 Jul;56(7):885-887.

17. Kim JE, Gottschall JA, Bachman RP, Nemzer L, Puligandla B, Schauer G. Facial infiltrating lipomatosis: physical, radiological, and histopathological findings. Arch Otolaryngol Head Neck Surg 2010 Mar;136(3):301-303.

18. Coffin, CM. Adipose and myxoid tumors. Pediatric soft tissue tumors: a clinical, pathological, and therapeutic approach. Baltimore: Williams and Wilkins Co; 1997. p. 245.

19. Mahadevappa A, Raghavan VH, RavishankarS, ManjunathGV. Congenital infiltrating lipomatosis of the face: a case report. Case Rep Pediatr 2012;Article ID 134646:3 pages. 